Ivan Luiz Gonçalves Pinto

O Progresso da Ciência e o Anarquismo Epistemológico de Karl Paul Feyerabend DISSERTAÇÃO DE MESTRADO DEPARTAMENTO DE FILOSOFIA Programa de Pós-Graduação em Filosofia 


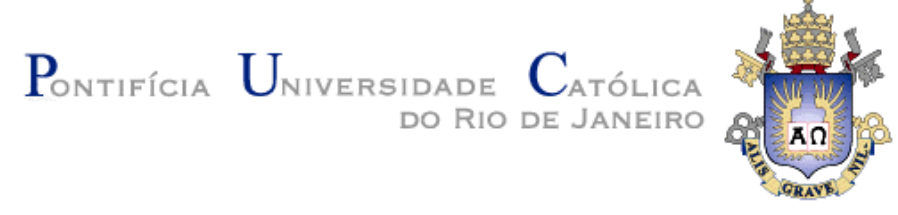

Ivan Luiz Gonçalves Pinto

\section{O progresso de Ciência e o Anarquismo Epistemológico de Karl Paul Feyerabend}

\section{Dissertação de Mestrado}

Dissertação apresentada ao Programa de Pós-graduação em Filosofia da PUCRio como requisito parcial para obtenção do título de Mestre em Filosofia.

Orientador: Prof. Carlos Alberto Gomes dos Santos 


\section{Pontifícia U UIVERsidade Católica $_{\text {a }}$

\section{O Progresso da Ciência e o Anarquismo Epistemológico de Karl Paul Feyerabend}

Dissertação apresentada como requisito parcial para obtenção do grau de Mestre pelo Programa de Pós-graduação em Filosofia da PUC-Rio. Aprovada pela Comissão Examinadora abaixo assinada.

Prof. Carlos Alberto Gomes dos Santos Orientador Departamento de Filosofia - PUC- Rio

Prof. Filipe Ceppas de Carvalho e Faria Departamento de Filosofia - PUC- Rio

Prof. Norman Roland Madarasz UGF

Prof. Paulo Fernando Carneiro de Andrade Coordenador Setorial do Centro de Teologia e Ciências Humanas da - PUC - RIO.

Rio de Janeiro, 9 de fevereiro de 20007. 
Todos os direitos reservados. È proibida reprodução total ou parcial do trabalho sem autorização da universidade, do autor e do orientador.

\section{Ivan Luiz Gonçalves Pinto}

Graduou-se em Matemática na Universidade Federal do Rio de Janeiro em 1985. Especializou-se Orientação Educacional em 1994. Especializou-se em Filosofia Contemporânea na UERJ em 2005.

Ficha Catalográfica

Pinto, Ivan Luiz Gonçalves.

O progresso de ciência e o anarquismo epistemológico de Karl Paul Feyerabend / Ivan Luiz Gonçalves Pinto; orientador: Carlos Alberto Gomes dos Santos. - 2007. 97 f.; $30 \mathrm{~cm}$

1. Dissertação (Mestrado em Filosofia)-Pontifícia Universidade Católica do Rio de Janeiro, Rio de Janeiro, 2007. Inclui bibliografia

1. Filosofia - Teses. 2. Progresso. 3. Ciência. 4. Epistemologia. 5. Pluralismo. 6. Anarquismo. I. Santos, Carlos Alberto Gomes dos. II. Pontifícia Universidade Católica do Rio de Janeiro. Departamento de Filosofia. III. Título. 


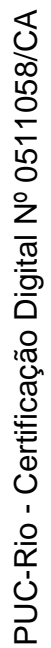

Para minha mãe Arilda e para meus filhos Ivan, Bernardo e Clara. 


\section{Agradecimentos}

Ao meu orientador Professor Carlos Alberto Gomes dos Santos pelo apoio e estímulo para a realização deste trabalho.

À PUC - Rio, seus professores e funcionários sempre muito zelosos e gentis, em especial ao Departamento de Filosofia.

Aos Professores Filipe Ceppas e Norman Madarasz que participaram da Comissão Examinadora.

Aos colegas do Mestrado, em especial ao Gaspar pelo apoio.

Ao amigo Alfredo pelo exemplo moral e pela ajuda espiritual.

A todos que colaboraram para a realização deste trabalho.

Agradeço, especialmente, à minha companheira Glória pela certeza de que sem ela eu nada teria realizado. 


\section{Resumo}

Pinto, Ivan Luiz Gonçalves. Santos, Carlos Alberto Gomes dos. O Progresso da Ciência e o Anarquismo Epistemológico de Karl Paul Feyerabend. Rio de Janeiro, 2007. 97p. Dissertação de Mestrado Departamento de Filosofia, Pontifícia Universidade Católica do Rio de Janeiro.

Esta dissertação apresenta um panorama da epistemologia contemporânea e mostra as idéias do filósofo Karl Paul Feyerabend em relação ao progresso da ciência. O nosso texto procura responder, principalmente, à seguinte questão: como um filósofo que vê a ciência como um empreendimento anárquico e sem fundamento pensa sobre o progresso científico? Para isso fazemos uma reconstrução histórica do ambiente cultural com o qual Feyerabend esteve envolvido e da sua carreira filosófica. Esta reconstrução procura mostrar as condições que produziram o Círculo de Viena que, por sua vez, influenciou muitos pensadores preocupados com as questões da ciência e seu progresso, como Popper, Kuhn, Lakatos e Laudan. Estes filósofos terão suas epistemologias brevemente analisadas, pois foram importantes na formação do pensamento feyerabendiano. Concluímos com uma defesa do anarquismo epistemológico, pois consideramos que a questão do progresso da ciência em Feyerabend deve ser entendida a partir das bases desta doutrina.

\section{Palavras-chave}

Progresso; ciência; epistemologia; pluralismo; anarquismo. 


\section{Abstract}

Pinto, Ivan Luiz Gonçalves. Santos, Carlos Alberto Gomes dos (Adviser) The Progress of Science and Karl Paul Feyerabend's Epistemological Anarchism. Rio de Janeiro, 2007. 97p. Dissertação de Mestrado Departamento de Filosofia, Pontifícia Universidade Católica do Rio de Janeiro.

This dissertation gives a panorama of contemporary epistemology and present philosopher Karl Paul Feyerabend's ideas on the progress of science. We attempt to address mainly the following topic: what are the thoughts of a philosopher on scientific progress who sees science as an enterprise of anarchy and without a foundation? In our attempt at providing an answer, we make a historical reconstruction of the cultural atmosphere in which Feyerabend was involved and of his philosophical career. This reconstruction shows the conditions that produced the Vienna Circle, which influenced many thinkers at the time who were concerned with the subjects of science and progress, like Popper, Kuhn, Lakatos and Laudan. These philosophers will have their epistemologies briefly analyzed since they were important in the formation of Feyerabendian thought. We conclude with a defense of epistemological anarchism as we contend that the subject of science's progress in Feyerabend should be understood from the bases of this doctrine.

\section{Keywords}

Progress; science; epistemology; pluralism; anarchism. 


\section{Sumário}

1. Introdução 9

2. A Viena do Círculo 12

3. O Círculo de Viena 14

4. Os Principais Interlocutores 18

4.1. Popper (O Progresso Racional) 18

4. 2. Kuhn (Progresso x Revoluções) 28

4.3. Lakatos (Progresso e Programas de Pesquisa) 38

4.4. Laudan (Progresso como Solução de Problemas) 44

5. Feyerabend 53

5.1. A Trajetória 53

5.2. Progresso Relativo 71

5.3. A Arte 73

5.4. A Filosofia 75

5.5. A Ciência 79

6. Conclusão 88

7. Referências bibliográficas 95 